\title{
PENGGUNAAAN MEDIA CERITA ANAK DALAM MENINGKATKAN KEMAMPUAN LITERASI DWIBAHASA GURU TAMAN KANAK-KANAK
}

\author{
Helda Jolanda Pentury \\ Universitas Indraprasta PGRI \\ E-mail: pentury.jolanda@yahoo.com
}

Article received: 25 Agustus 2017 Review process: 15 Januari 2018

Article published: 30 March 2018

\begin{abstract}
Media learning for children is not to go through only in the academic field. Many ways by teachers, for the children to obtain knowledge of the method interestingly. If the students feel really enjoy, then their learning to get the knowledge would be maximized.In addition, the ability pedagogical teachers is expected to be able to create learning creative and innovative. One method of learning fun is through the story.Professional teachers through competence of using bilingual skills charged in the era of technology connection with the capacity of them as educator.This research is using the qualitative descriptive. The study is done in some kindergartens, in kecamatan Limo depok. Data collection method done by means of interview, observation and documentation. The result of this research is expected to stimulate the ability of their pedagogical and increase professionalism in developing the ability of bilingual literacy.
\end{abstract}

Keywords: Children story, Literacy, Bilingual.

\begin{abstract}
Abstrak
Media pembelajaran untuk anak-anak ternyata tidak harus melalui bidang akademik. Banyak cara yang bisa dilakukan oleh para guru, agar anak mendapatkan pengetahuan dengan metode yang menyenangkan.Jika anak didik merasa senang saat menjalani sesuatu, tentu ilmu yang diperoleh akan maksimal. Selain itu, kemampuan pedagogik guru pun diharapkan mampu menciptakan pembelajaran kreatif dan inovatif. Salah satu metode pembelajaran menyenangkan adalah melalui cerita. Profesionalisme guru melalui kompetensi penggunaan dwibahasa dituntut dalam era teknologi berkaitan dengan kapasitas sebagai pendidik. Penelitian ini menggunakan pendekatan penelitian kualitatif deskriptif. Penelitian ini dilakukan di beberapa TK, di kecamatan Limo Depok. Metode pengumpulan data dilakukan dengan cara wawancara, observasi dan dokumentasi. Hasil penelitian ini diharapkan mampu menstimulasi kemampuan pedagogik para pendidik dan meningkatkan profesionalisme pendidik dalam berkarya menumbuhkembangkan kemampuan literasi dwibahasa kepada anak-anak.
\end{abstract}

Kata Kunci: Cerita anak, Literasi, Dwibahasa 


\section{PENDAHULUAN}

Kemampuan menulis cerita atau dongeng dan menceritakannya merupakan salah satu keterampilan yang harus dimiliki dan dikuasai oleh seorang guru, khususnya seorang guru Taman Kanak-Kanak. Bercerita atau mendongeng merupakan salah satu media pembelajaran yang sampai saat ini masih disukai oleh anak-anak, lebih-lebih anak usia TK. Dengan bercerita atau mendongeng guru dapat berkomunikasi dengan baik kepada siswanya untuk menyampaikan pesan pendidikan dengan mudah. Dengan demikian, bercerita atau mendongeng dapat dijadikan media pembelajaran yang baik dalam menyampaikan materi budi pekerti kepada para siswa. Melalui survei yang dilakukan di sekolah, kegiatan pembelajaran untuk anak didik masih belum maksimal kreatifitasnya. Kegiatan pembelajaran yang dilakukan seputar bernyanyi, belajar mengenal huruf dan angka (kurang memadukan ranah kognitif, afektif, dan psikomotorik sekaligus). Kegiatan menulis merupakan salah satu kegiatan yang dapat menggali kompetensiseseorang dari segi kognitif, afektif, dan psikomotorik. Salah satunya adalah dengan membuat cerita anak. Karena melalui pembuatan cerita anak, kreatifitas menulis para guru dan anak didik dapat tersalurkan. Mereka dapat menciptakan karya-karya sastra. Kegiatan menulis memerlukan banyak tenaga, waktu, serta perhatian yang sungguh-sungguh dan juga menuntut keterampilan yang tidak dimiliki semua orang. Bahkan di kalangan guru-guru masih banyak yang mengalami kesulitan menulis dengan benar.

Pada dasarnya banyak pendidik yang memiliki potensi untuk menulis, hanya saja potensinya belum terasah karena tidak ada upaya untuk meningkatkan keterampilan mereka dan tidak ada media sebagai tempat untuk menyalurkan ide, gagasan dan kreativitasnya. Dengan kondisi yang demikian perlu pelatihan untuk meningkatkan kemampuan menulis dan menerapkan metode bercerita kreatif di dalam upaya meningkatkan kemampuan dwibahasa para guru TK.

Kemampuan menulis cerita dan menceritakannya merupakan salah satu keterampilan yang harus dimiliki dan dikuasai oleh seorang guru, khususnya seorang guru Taman KanakKanak. Bercerita merupakan salah satu media pembelajaran yang sampai saat ini masih disukai oleh anak-anak, lebih-lebih anak usia TK. Dengan bercerita guru dapat berkomunikasi dengan baik kepada siswanya untuk menyampaikan pesan pendidikan dengan mudah. Dengan demikian, bercerita dapat dijadikan media pembelajaran yang baik dalam menyampaikan materi budi pekerti kepada para siswa.Oleh sebab itu, agar para siswa mau dan senang mendengarkan cerita yang disampaikan oleh gurunya, maka cerita dan teknik penyampaiannya harus baik dan menarik 
siswa. Akan tetapi, kenyataan yang ada di masyarakat ketika peneliti survei terhadap kegiatan pembelajaran di beberapa TK, hampir sebagian guru TK di Depok belum menguasai kemampuan menulis cerita menceritakannya di hadapan para anak didiknya dengan baik.

Cerita anak dapat dibuat dengan dwibahasa atau bilingual. Dewasa ini Bahasa Inggris sudah diterima sebagai Bahasa Internasional yang terkemuka karena dianggap menjadi sarana komunikasi terpenting masyarakat Indonesia untuk merespon tuntutan kemajuan zaman. Untuk itulah bahasa Inggris sudah diperkenalkan secara luas mulai usia dini baik di sekolah-sekolah formal maupun non-formal. Berbagai penelitian telah membuktikan bahwa usia dini merupakan usia paling peka belajar bahasa. Maka atas dasar itulah pengajaran Bahasa Inggris untuk anakanak usia dini mulai TK dan Sekolah Dasar sudah secara luas ditawarkan di berbagai sekolah di perkotaan.

Teori-teori Second Language Acquisition terbaru menyebutkan bahwa semakin dini anak belajar bahasa asing, semakin cepat mereka menguasainya karena alasan kemampuan short and long term memory yang lebih baik. Disebutkan pula tekanan psikologis yang lebih sedikit dan faktor interaksi yang intens sangat disarankan untuk membantu anak-anak belajar bahasa asing.

Berangkat dari kenyataan itulah maka dipandang perlu dan mendesak untuk membekali guru-guru TK di wilayah Limo Depok dengan kemampuan dan keterampilan menulis cerita dan teknik-teknik penyajian cerita dengan metode cerita kreatif di dalam upaya mengembangkan kedwibahasaan guru.

\section{METODOLOGI}

Penelitian ini merupakan penelitian kualitatif (field research) yang pada hakikatnya merupakan metode untuk menemukan secara spesifik dan realistis tentang apa yang sedang terjadi pada suatu tempat terjadinya gejala yang diselidiki (Mardalis, 2004: 24). Penelitian ini dilakukan yang dilakukan dalam bentuk pembinaan dan pelatihan. Pembinaan dilakukan terhadap materi penulisan naskah cerita dari aspek kesastraan, kebahasaan, dan teknik penulisan cerita. Penulisan cerita diusahakan berdasar prinsip through the eyes of the children (melalui kacamata anak-anak). Dengan demikian, cerita yang ditulis disesuaikan dengan daya jangkau, minat, perkembangan kognitif, emotif, dan sosial, serta penguasaan kalimat atau kosa kata yang telah dikuasai oleh anak (faktor kebahasaan). Harapannya, cerita itu menjadi lebih mudah dicerna dan menarik, sehingga, manfaat-manfaat yang terdapat dalam dongeng itu sampai kepada anak. 
kegiatan pelatihan pembuatan cerita anak dan metode bercerita dalam mengembangkan kedwibahasaan guru TK Se-kota Depok akan dilaksanakan dalam bentuk workshop. Dengan workshop, materi yang sifatnya teoritik disampaikan dan didiskusikan. Setelah workshop, kegiatan ini juga diwujudkan dalam bentuk demonstrasi atau praktik pelatihan menulis cerita anak serta teknik-teknik bercerita.

\section{HASIL DAN PEMBAHASAN}

Kegiatan ini berpusat di TK Al Amanah yang beralamat di Jl. Abus 28 RT 007 RW 03 Limo Sawangan Depok Jawa Barat, Indonesia. Telepon (021) 7530708. Kurang lebih hanya berjarak $10 \mathrm{~km}$ dari pusat kota Depok (Margonda). Peserta yang mengikuti kegiatan sebanyak 29 orang dengan rincian sebagai berikut: TK Amanah sebanyak 10 orang, TK Asa'adah sebanyak 15 orang, TK Anak Indonesia sebanyak 4 orang.

Pelaksanaan kegiatan ini ditujukan untuk berbagi wawasan tentang pembuatan cerita anak dan keterampilan bercerita untuk para guru TK. Titik tekan kegiatan ini adalah pada pembelajaran berbasis kegiatan interaktif dan menyenangkan. Hasil kegiatan ini dapat dijabarkan satu per satu sebagai berikut:

1. Peserta mampu memahami kreatifitas sebagai seorang pendidik.

2. Peserta mampu membuat cerita anak dalam dwi bahasa (Bahasa Indonesia dan Bahasa Inggris).

3. Peserta mampu bercerita dengan menarik dan menyenangkan.

\section{Pelatihan hari Ke-1}

Kegiatan diawali dengan perkenalan pemanasan atau ice breaking senam otak. Kemudian masuk ke kegiatan inti, penulisan cerita anak oleh para guru TK sebelum materi diberikan (pra siklus). Para peserta workshop semua membuat cerita anak dengan tema bebas. Setelah itu, pembicara mulai memberikan materi mengenai cerita anak, mulai dari unsur-unsur cerita anak hingga manfaat menulis cerita anak.

Materi metode bercerita hingga teknik dan media bercerita di hadapan anak, serta materi penulisan cerita anak dalam bahasa Inggris disambung dengan sesi diskusi atau tanya jawab antara pembicara dengan peserta workshop. Cukup banyak pertanyaan dari para peserta workshop. Mereka sangat antusias dan termotivasi untuk bisa menuliscerita anak dalam dwibahasa. 
Tabel 1. Kegiatan Hari 1

\begin{tabular}{|c|c|c|c|}
\hline Kegiatan & Materi & Metode & Ketrampilan Literasi \\
\hline $\begin{array}{l}\text { Pembukaan } \\
\text { Senam otak }\end{array}$ & Ice breaking & $\begin{array}{l}\text { Bernyanyi dan } \\
\text { senam otak }\end{array}$ & \\
\hline $\begin{array}{l}\text { Pemaparan tujuan } \\
\text { kegiatan }\end{array}$ & $\begin{array}{l}\text { Teori Literasi } \\
\text { Teori Menulis } \\
\text { Metode Bercerita }\end{array}$ & Ceramah & $\begin{array}{l}\text { Mendengar dan Mencatat } \\
\text { Penjelasan }\end{array}$ \\
\hline $\begin{array}{l}\text { Menulis cerita } \\
\text { dengan tema bebas } \\
\text { (pre-writing) }\end{array}$ & $\begin{array}{l}\text { Cerita anak: fiksi, } \\
\text { non fiksi }\end{array}$ & Demonstrasi & Menulis \\
\hline $\begin{array}{l}\text { Pemaparan materi } \\
\text { dwibahasa }\end{array}$ & $\begin{array}{l}\text { Kosa kata dasar } \\
\text { berupa kata, frase } \\
\text { dan kalimat } \\
\text { sederhana }\end{array}$ & Latihan menulis & Menulis \\
\hline Sesi Tanya Jawab & Diskusi & $\begin{array}{l}\text { Pertanyaan } \\
\text { langsung dijawab }\end{array}$ & \\
\hline $\begin{array}{l}\text { Melakukan kegiatan } \\
\text { menulis ( during } \\
\text { writing) }\end{array}$ & $\begin{array}{l}\text { Teks deskripsi } \\
\text { dwibahasa dengan } \\
\text { tema buah/ binatang }\end{array}$ & Praktik menulis & Menulis \\
\hline $\begin{array}{l}\text { Penulisan dikoreksi } \\
\text { dan direvisi (post- } \\
\text { reading) }\end{array}$ & $\begin{array}{l}\text { Teks deskripsi } \\
\text { dwibahasa dengan } \\
\text { tema buah/ binatang }\end{array}$ & $\begin{array}{l}\text { Praktik Menulis, } \\
\text { penulisan lebih } \\
\text { terarah dan } \\
\text { penggunaan } \\
\text { kalimat lebih } \\
\text { efektif }\end{array}$ & Menulis \\
\hline
\end{tabular}

\section{Pelatihan Hari Ke-2}

Hari kedua workshop lebih banyak diisi dengan praktek. Pekerjaan peserta workshop menulis cerita anak dikumpulkan dan dinilai oleh pembicara. Kemudian dilanjutkan dengan praktek bercerita di dalam masing-masing kelompok yang telah dibentuk sebelumnya. Mereka saling bergantian untuk bercerita (simulasi) dengan menggunakan media buku cerita yang pembicara sediakan. Pembicara sambil menilai kegiatan mereka.

Setelah praktek bercerita telahselesai, pembicara mengumumkan hasil karya yang mendapat nilai tertinggi. Pembicara juga memberikan evaluasi kepada para peserta mengenai hasil karya dan praktek mereka bercerita. Memberikan masukan atau saran dan kritik untuk para peserta workshop agar dapat diterapkan di kelas masingmasing di dalam kegiatan belajar mengajar. Evaluasi mengenai acara kegiatan workshop ini juga disampaikan oleh para peserta, memberikan saran dan kritik bagi pembicara.

Tabel 2 Kegiatan hari ke 2

\begin{tabular}{|l|l|l|l|}
\hline \multicolumn{1}{|c|}{ Kegiatan } & \multicolumn{1}{|c|}{ Materi } & \multicolumn{1}{c|}{ Metode } & \multicolumn{1}{c|}{$\begin{array}{c}\text { Ketrampilan } \\
\text { Literasi }\end{array}$} \\
\hline $\begin{array}{l}\text { Pembukaan } \\
\text { Evaluasi penulisan }\end{array}$ & Evaluasi penulisan & $\begin{array}{l}\text { Dianalisis } \\
\text { bersama }\end{array}$ & Menulis \\
\hline
\end{tabular}




\begin{tabular}{|c|c|c|c|c|}
\hline & & $\begin{array}{l}\text { berdasarkan } \\
\text { kriteria penulisan } \\
\text { kreatif yang telah } \\
\text { ditentukan }\end{array}$ & & \\
\hline Pemaparan Metode Bercerita & $\begin{array}{l}\text { Metode Bercerita } \\
\text { Cerita anak dan } \\
\text { kriterianya }\end{array}$ & Show and Tell & Bercerita & \\
\hline $\begin{array}{l}\text { Pemaparan materi bercerita } \\
\text { dwibahasa }\end{array}$ & $\begin{array}{l}\text { Cerita anak dari } \\
\text { buku cerita yang } \\
\text { telah disediakan }\end{array}$ & Show and tell & $\begin{array}{l}\text { Bercerita } \\
\text { membaca }\end{array}$ & sambil \\
\hline $\begin{array}{l}\text { Simulasi bercerita dalam } \\
\text { kelompok secara bergantian }\end{array}$ & Buku cerita anak & Show and tell & $\begin{array}{l}\text { Bercerita } \\
\text { membaca }\end{array}$ & sambil \\
\hline $\begin{array}{l}\text { Lomba bercerita dan lomba } \\
\text { penulisan per kelompok }\end{array}$ & $\begin{array}{l}\text { Karya tulis peserta } \\
\text { Media buku cerita }\end{array}$ & $\begin{array}{l}\text { Creative show } \\
\text { and tell }\end{array}$ & $\begin{array}{l}\text { Bercerita } \\
\text { membaca }\end{array}$ & sambil \\
\hline
\end{tabular}

Tabel 3 Hasil Penulisan Cerita Anak (pre-writing)

\begin{tabular}{|l|c|c|c|}
\hline \multicolumn{1}{|c|}{ Kriteria } & Sangat Sesuai & Sesuai & Tidak Sesuai \\
\hline Isi cerita sesuai Tema & & 14 & 5 \\
\hline Kohesi dan Koherensi dalam teks & & 10 & 9 \\
\hline Penggunaan Diksi & 2 & 7 & 10 \\
\hline Penggunaan tanda Baca & 2 & 10 & 7 \\
\hline Penggunaan Dwibahasa & & 2 & 17 \\
\hline
\end{tabular}

*Keterangan: Angka adalah jumlah peserta (guru-guru)

Tabel 4 Hasil Penulisan Cerita Anak (post-writing)

\begin{tabular}{|l|c|c|c|}
\hline \multicolumn{1}{|c|}{ Kriteria } & Sangat Sesuai & Sesuai & $\begin{array}{c}\text { Tidak } \\
\text { Sesuai }\end{array}$ \\
\hline Isi cerita sesuai Tema & 3 & 16 & \\
\hline Kohesi dan Koherensi dalam teks & 4 & 15 & \\
\hline Penggunaan Diksi & 5 & 14 & \\
\hline Penggunaan tanda Baca & 5 & 12 & \\
\hline Penggunaan Dwibahasa & & 14 & 5 \\
\hline
\end{tabular}

Tabel 5 Hasil Bercerita Cerita Anak (pre-story telling)

\begin{tabular}{|l|c|c|c|}
\hline \multicolumn{1}{|c|}{ Kriteria } & Sangat Sesuai & Sesuai & $\begin{array}{c}\text { Tidak } \\
\text { Sesuai }\end{array}$ \\
\hline $\begin{array}{l}\text { Penguasaan materi dalam bercerita } \\
\text { (Performance) }\end{array}$ & & 14 & 5 \\
\hline Pengucapan (Pronouciation) & & 10 & 9 \\
\hline Ekspresi Bercerita (Expression) & & 14 & 5 \\
\hline Penggunaan intonasi (intonation) & 2 & 14 & 3 \\
\hline Penggunaan Dwibahasa (bilingual) & & 12 & 8 \\
\hline
\end{tabular}


Tabel 6 Hasil Bercerita Cerita Anak (post-story telling)

\begin{tabular}{|l|c|c|c|}
\hline \multicolumn{1}{|c|}{ Kriteria } & Sangat Sesuai & Sesuai & $\begin{array}{c}\text { Tidak } \\
\text { Sesuai }\end{array}$ \\
\hline $\begin{array}{l}\text { Penguasaan materi dalam bercerita } \\
\text { (Performance) }\end{array}$ & 1 & 16 & 2 \\
\hline Pengucapan (Pronouciation) & 4 & 14 & 5 \\
\hline Ekspresi Bercerita (Expression) & 5 & 15 & \\
\hline Penggunaan intonasi (intonation) & 2 & 12 & 5 \\
\hline Penggunaan Dwibahasa (bilingual) & & & \\
\hline
\end{tabular}

Berdasarkan hasil yang ada pada tabel-tabel di atas, maka hasil dalam penulisan setelah pelatihan menunjukkan hasil yang signifikan. Hasil dari bercerita dengan menggunakan metode bercerita yang kreatif pun menunjukkan hasil yang signifikan. Akan tetapi penggunaan dwibahasa belum menunjukkan hasil yang signifikan dikarenakan para guru tidak pernah menggunakan bahasa Inggris dalam kegiatan menulis cerita, membaca cerita bahkan dalam penggunaannya sehari-hari. Hal positif yang diperoleh dalam kegiatan ini adalah para guru termotivasi untuk belajar menggunakan dwibahasa dan berusaha membiasakannya pada muridmurid mereka.

\section{SIMPULAN}

Berdasarkan hasil umpan balik didapatkan informasi bahwa kegiatan ini sangat relevan dengan kebutuhan para peserta. Para guru merasa mendapat wawasan dan skill yang aplikatif dan bermanfaat. Selain itu mereka juga merasa senang dengan teknik dan metode pelatihan yang diterapkan selama pelatihan.Kemampuan yang dilatihkan dan dimiliki peserta diantaranya adalah:

1. Kepercayaan diri para guru di dalam membuat cerita anak.

2. Pengetahuan dan skill tentang cara pengajaran bahasa Inggris dan bahasa Indonesia melalui penulisan cerita anak.

3. Peningkatan kemampuan bercerita dengan metode yang menarik dan media yang kreatif.

4. Penggalian kompetensi akademik untuk lebih kreatif di dalam pembelajaran anak usia dini.

\section{DAFTAR PUSTAKA}

Andi.http://umprodipaud.blogspot.co.id/2010/11/pengembangan-kemampuan-kemampuanberbahasa-anak.html,diakses pada 10 September 2016.

Bachri, S Bachtiar. 2005. Pengembangan Kegiatan Bercerita, Teknik dan Prosedurnya. Jakarta: Depdikbud. 
Chaer, Abdul dan Leonie Agustina. 2004. Sosiolinguistik Perkenalan Awal. Jakarta: Rineka Cipta.

Dhieni, Nurbiana dkk. 2006. Metode Pengembanga Bahasa.. Jakarta: Universitas Terbuka.

Lukens, Rebecca J. 2003. A Critical Handbook of Children's Literature. New York: Longman.

Moeslichatoen.2004. Metode Pengajaran. Jakarta: Rineka Cipta.

Musfiroh, Tadkiroatun. 2005. Bercerita Untuk Anak Usia Dini. Jakarta: Depdiknas.

Nurgiantoro, Burhan. 2005. Sastra Anak: Pengantar Pemahaman Dunia Anak. Yogyakarta: Gadjah Mada University Press.

Puryanto, Edi. 2008. Konsumsi Anak dalam Teks Sastra di Sekolah. Makalah dalam Konferensi Internasional.

Sarumpaet, Riris K. Toha. 2003. Struktur Bacaan Anak, dalam "Teknik Menulis Cerita Anak". Yogyakarta: Pink Books, Pusbuk, dan Taman Melati.

Suhartono. 2005. Pengembangan Keterampilan Bicara Anak Usia Dini. Jakarta: Diknas.

Tampubolon. 1991. Mengembangkan Minat dan Kebiasaan Membaca pada Anak. Bandung: Angkasa. 